\title{
FACTORS INFLUENCING THE USE OF LAST PLANNER SYSTEM METHODS: AN EMPIRICAL STUDY IN PERU
}

\author{
Danny Murguia ${ }^{1}$
}

\begin{abstract}
The Last Planner System ${ }^{\mathrm{TM}}$ (LPS) is a collaborative production and control system that has been implemented by some contractors in Peru in the last two decades. However, the full potential of its implementation has not been totally achieved. The aim of this research is to identify the most prominent factors that dictate the level of use of LPS methods. To achieve this objective, a survey was designed using variables found in previous research and informed by interviews with LPS experts. Ninety-five site engineers responded to the questionnaire. Data was analysed using reliability analysis and multiple linear regression. It was found that 'Trained staff', 'Good Decision-Making', and 'Commitment' are the factors with the highest scores. Nevertheless, 'Integration and Communication,' and 'LPSknowledge' were found to be important to bring the successful implementation of LPS methods whilst 'Resistance to Change' and the 'firm size' constraint implementation. The findings suggest that 'Integration and Communication', 'LPS-knowledge', and 'Resistance to Change' are not independent factors, thus, the need to explore second-order factors influencing their variability. Such dependency could be found at the firm and institutional levels. Further research can be extended to the development of a prescriptive model for LPS implementation in construction firms.
\end{abstract}

\section{KEYWORDS}

Last planner system, methods, onsite, facilitators, barriers.

\section{NEARLY TWO DECADES OF LPS EXPERIENCE IN PERU}

The LPS was first introduced in Peru in the early 2000's with the publication of the seminal book "Productivity in Construction Projects" (Guio 2001). The study showed a staggering $28 \%$ of adding-value activities and $36 \%$ of waste of labour productivity. Guio (2001) suggested the use of Last Planner as a system to overcome the low levels of productivity in the industry. The approach implemented by the early adopters had a focus on the division of zones per story - to create a stable flow - and on the improvement of labour productivity. As such, early adopters implemented takt-time scheduling (locally known as "the train"),

Assistant Professor, Department of Engineering, Division of Civil Engineering, Pontifical Catholic University of Peru, dmurguia@ pucp.pe 
and the work-sampling method. However, the production system design was not entirely collaborative. Rather, it relied only on the decisions of the site manager and the site foreman. Moreover, the first LPS methods implemented have been milestone pull planning, look ahead planning, weekly work plans and measurement of PPC (Yoza 2011).

Over the next years, some institutional factors shaped LPS as a normative pressure in the Peruvian construction industry. Such factors include large contractors' decision to standardise LPS as a production management system, the creation of the LCI (Peru) Chapter, and the inclusion of Lean Construction and LPS as modules at undergraduate and master's programmes. As such, LPS focus shifted from takt-time scheduling and the worksampling method, to efficient flows and processes, and collaborative onsite planning with both in-house foremen and subcontractors (Flores \& Ollero 2013; Murguia et al. 2016). LPS implementation, however, has not been without shortfalls. Frequently, weekly meetings omit the analysis of constraints, activities are not revealed at the operational level, and there is a lack of commitment of subcontractors and site engineers. As a result, LPS is partially implemented, the collaborative planning declines, the desired "pull" system becomes a "push" system, and its use decreases in the finishing and fit-out phases (Murguia et al. 2016).

As such, the question remains on what are the factors that constraint the use of LPS to its full potential after nearly two decades of diffusion in the industry. Therefore, the overarching aim of this research is to identify the main factors that dictate the use of LPS methods on site. To achieve this aim, first, a literature review was conducted to find out the most important enablers and barriers discussed in the Lean community. Second, short semi-structure interviews with LPS experts were conducted to inform the catalogue of factors and to identify contextual factors. Third, a questionnaire was designed aimed at site engineers using LPS. The questionnaire was piloted to improve readability and comprehensibility. Fourth, empirical data was collected with ninety-five site engineers currently working on construction projects. Fifth, data was analysed using reliability analysis and multiple regression. Finally, the findings are discussed, and directions for further research are presented.

\section{RESEARCH METHOD}

A mixed method approach is selected as the research method. A mixed method combines the flexibility of qualitative research and the structure of quantitative research (Cresswell 2014). As such, a literature review and exploratory interviews with experts on LPS implementation will inform the design of the instrument for data collection. A questionnaire will help to obtain empirical evidence on a larger scale from a variety of projects and respondents. The objective of the data collection instrument is to measure the intensity of the factors under study, rather than to assess participant's perceptions on the importance of such factors. Therefore, relationships between dependent and independent factors can be made. 


\section{LITERATURE REVIEW}

The LPS is a production planning and control system designed to produce predictable workflow and rapid learning in programming, design, construction, and commissioning of construction projects (Ebbs and Pasquire 2019). LPS has five elements: (1) Master Scheduling (set milestones and phase durations \& overlaps), (2) Phase Pull Planning (specify handoffs \& conditions of satisfaction between processes within phases), (3) Lookahead Planning (task breakdown from processes into operations, constraint analysis and removal), (4) Commitment Planning (make reliable promises, underloading resources, daily huddles), and (5) Learning (analysis of breakdowns: percentage of plan completed, 5 Whys, frequency of plan failures) (Ballard and Tommelein 2016). It is argued that a systemic implementation with sustainable results must complete the learning process throughout the five stages. A wide range of academic literature have shown exemplar case studies of LPS implementation in the industry (e.g. Alarcon et al. 2005). However, Dave et al. (2015) posited that 'the full potential of LPS is rarely achieved and the root causes for this are not entirely understood'. Dave et al. (2015) found that firms implementing lean for over 10 years, have only implemented three main tools of the LPS toolset, with a focus on the short-term planning (weekly meetings). Based on literature review and field observations on construction projects in the UK and Finland, the study catalogued several recurrent problems in LPS implementation:

- Lack of ability to deploy collaborative aspects

- Limited deployment of LPS

- Reduced importance of phase and master plans

- Lack of continuous improvement

- Lack of links between detailed and high-level plans

A similar finding was showed by Perez and Ghosh (2018) who examined typical shortfalls of LPS implementation such as an incomplete PPC process, the underutilisation of lookahead plans, lack of a guideline practice for schedule updating, and lack of a structured order for the introduction of LPS on site. Some authors have identified factors that would explain the partial deployment of LPS. For example, Cano et al. (2015) catalogued a set of barriers and critical success factors for Lean Construction implementation. As such, the study identified 'development and selection of the right people' as the most influential success factor and 'cultural problems' was deemed to be the most important barrier. Similarly, Brady et al. (2011) identified the main barriers for LPS implementation, namely, weak communication and transparency, minimum involvement of construction workers and subcontractors, inadequate training of participants, lack of role definition, inadequate use of information, lack of time for implementing improvements, and lack of integration of the supply chain.

Alarcon et al. (2002) conducted a study in twelve construction companies and identified human factors as important barriers that obstruct LPS implementation. Notably, resistance to change is observed as one of the main obstacles, followed by lack of self-criticism, shortterm vision and misinterpretation of the PPC indicator. Alarcon et al. (2005) studied 77 Chilean projects and found that lack of time to implement changes, lack of training, 
inadequate structure at the organisational level, low understanding of LPS concepts, inadequate administration, weak communication and lack of integration were deficiencies found in LPS implementation.

From the literature, it is observed multifaceted factors linked to people, firms and institutions. However, little is known of what are the specific factors that systematically hinder the deployment of LPS. Moreover, there is little knowledge on the impact of the firm size on LPS implementation. The knowledge of this factors would help site engineers and decision-makers to make improved decisions when implementing LPS on site.

\section{EXPLORATORY INTERVIEWS}

Three LPS experts were interviewed to gain insights into the challenges of LPS implementation onsite. The experts were selected on the basis to be construction professionals with renowned experience as contractors and consultants. The first expert argued that the main barrier is the human factor due to lack of commitment and insufficient training. The production system is collaboratively designed in the kick-off pull planning meeting, however, efforts decline to sustain the flow during execution and control. The second barrier is the belief that LPS is a reporting system (e.g. PPC or lookahead speaadsheets) for the top management, instead of the tools being facilitators for the learning process. The third problem is the institutionalised problem of lack of anticipation to problems and insufficient responsiveness of the logistics department to remove constraints. Thus, this lack of commitment leads to a focus on looking for the 'guilty' instead of identifying root causes and solving problems. To mitigate this, some facilitators are described such as the definition of lead times in logistics, training to staff and subcontractors, and a clear definition of short-term metrics.

The second expert stated that LPS is a learning process to improve planning. The first barrier to achieve good results is a lack of commitment. The expert argued that to solve this, psychological and sociological studies are needed. As such, people need to understand that LPS meetings are meant to achieve collaboration, rather than to accuse others on what they did wrong. The expert comments that LPS is not properly implemented. Several site engineers believe that using a few tools make the site an LPS-enabled project. However, little attention is paid to the thorough LPS cycle.

The third expert posited that LPS helps to reduce the variability in the construction process, thus, helps to improve the schedule compliance. The expert contended that LPS implementation requires a cross-project implementation as top management should assign enough resources and support for effective implementation. In their view, changing people's mindset is a difficult task and takes time. The expert argues that LPS is not properly implemented, however, foremen and subcontractors have learnt that they must plan in hands with production engineers. Lack of lessons learnt and self-criticism are also pitfalls. Finally, the expert argued that the firm size also matters, as big companies implement LPS due to tangible benefits, however, small and middle enterprises are struggling to implement. 
Factors Influencing the Use of Last Planner System Methods: An Empirical Study in Peru.

Table 1: Catalogue of Factors for LPS implementation 


\begin{tabular}{|c|c|c|}
\hline Factor & Sources & Variable \\
\hline Leadership & $\begin{array}{l}\text { Fernandez-Solis et al. (2013), } \\
\text { Cano et al. (2015), Ebbs and } \\
\text { Pasquire (2019) }\end{array}$ & $\begin{array}{l}\text { Site engineer's leadership } \\
\text { Foremen and subcontractor's leadership } \\
\text { Top management leadership }\end{array}$ \\
\hline Commitment & $\begin{array}{l}\text { AlSehaimi et al. (2009), } \\
\text { Fernandez-Solis et al. (2013), } \\
\text { Interviews with experts }\end{array}$ & $\begin{array}{l}\text { Site engineer's commitment } \\
\text { Foremen and subcontractor's commitment } \\
\text { Top management commitment } \\
\text { Logistics department commitment } \\
\text { Central office commitment }\end{array}$ \\
\hline $\begin{array}{l}\text { Integration and } \\
\text { communication }\end{array}$ & $\begin{array}{l}\text { Alarcon et al. (2005), AlSehaimi } \\
\text { et al. (2009), Brady et al. } \\
\text { (2011), Fernandez-Solis et al. } \\
\text { (2013), Cano et al. (2015), Ebbs } \\
\text { and Pasquire (2019) }\end{array}$ & $\begin{array}{l}\text { Onsite stakeholder's integration } \\
\text { Compatible decisions between onsite } \\
\text { stakeholders } \\
\text { Permanent feedback between last planners } \\
\text { and site engineers }\end{array}$ \\
\hline $\begin{array}{l}\text { Good } \\
\text { information } \\
\text { and decision- } \\
\text { making }\end{array}$ & $\begin{array}{l}\text { Alarcon et al. (2005), Brady et } \\
\text { al. (2011), Fernandez-Solis et } \\
\text { al. (2013) }\end{array}$ & $\begin{array}{l}\text { Early identification of improvement } \\
\text { opportunities } \\
\text { Timely information to make decisions } \\
\text { A Big-room to facilitate decision-making }\end{array}$ \\
\hline Trained Staff & $\begin{array}{l}\text { Alarcon et al. (2005), Hamzeh } \\
\text { (2011), Brady et al. (2011), } \\
\text { Cano et al. (2015), Perez and } \\
\text { Gosh (2018) }\end{array}$ & $\begin{array}{l}\text { Trained site engineers } \\
\text { Trained foreman and subcontractors }\end{array}$ \\
\hline $\begin{array}{l}\text { LPS- } \\
\text { knowledge }\end{array}$ & $\begin{array}{l}\text { Alarcon et al. (2005), Friblick et } \\
\text { al. (2009), Fernandez-Solis et } \\
\text { al. (2013), }\end{array}$ & $\begin{array}{l}\text { There is enough LPS knowledge } \\
\text { Site engineers know that LPS is more than } \\
\text { takt-time scheduling }\end{array}$ \\
\hline Lack of time & $\begin{array}{l}\text { Alarcon et al. (2005), Brady et } \\
\text { al. (2011), Interviews with } \\
\text { experts }\end{array}$ & $\begin{array}{l}\text { We focus more on project's timely } \\
\text { completion rather than to fully implement } \\
\text { LPS } \\
\text { We focus more in logistics and contracts } \\
\text { rather than to fully implement LPS } \\
\text { We focus more in problems with the } \\
\text { neighbourhood rather than to fully } \\
\text { implement LPS }\end{array}$ \\
\hline $\begin{array}{l}\text { Firm's LPS- } \\
\text { culture }\end{array}$ & $\begin{array}{l}\text { Alarcon et al. (2005), Friblick et } \\
\text { al. (2009), Hamzeh (2011), } \\
\text { Interviews with experts }\end{array}$ & $\begin{array}{l}\text { LPS requires a pilot project implementation } \\
\text { LPS requires a standard procedure across } \\
\text { projects } \\
\text { LPS requires a knowledge manager across } \\
\text { projects }\end{array}$ \\
\hline $\begin{array}{l}\text { Resistance to } \\
\text { change }\end{array}$ & $\begin{array}{l}\text { Alarcon et al. (2002), AISehaimi } \\
\text { et al. (2009), Fernandez-Solis et } \\
\text { al. (2013), Cano et al. (2015), } \\
\text { Perez and Gosh (2018) }\end{array}$ & $\begin{array}{l}\text { Site engineer's resistance to change } \\
\text { Foremen and subcontractor's resistance to } \\
\text { change }\end{array}$ \\
\hline
\end{tabular}




\section{QUESTIONNAIRE DESIGN AND DATA COLLECTION}

A questionnaire was used as the main method for data collection. The questionnaire was designed using factors found in the literature and the exploratory interviews as shown in Table 1. The target population of respondents was site engineers who have practical experience using LPS in their current or last project. Variables were assessed using a fivepoint Likert Scale. Respondents were asked to assess from 1-5 to what extent the observed variables were present in their current/last project. For example, the variables "Foremen and subcontractor's commitment", or "Site engineer's leadership" were assessed as $1=$ Very Low, 2 = Low, 3 = Intermediate, $4=$ High, 5 = Very High. Similarly, the dependent factor - LPS methods - was assessed in a six-point Scale. To capture the implementation of the wide range of methods, participants were asked to assess the level of implementation of each method. For example, the variable "Constraint analysis and removal" was assessed as $0=$ Null, $1=$ Very Low, $2=$ Low, $3=$ Intermediate, $4=$ High, $5=$ Very High.

The questionnaire was piloted with five construction professionals with a wealth of experience using LPS. Some suggestions on the wording of variables and the scales were incorporated into the revised questionnaire. Finally, data was collected via three methods: 58 questionnaires were collected face-to-face at construction sites, 16 questionnaires were collected at an LCI (Peru) Chapter diffusion activity in December 2018, and 21 questionnaires were collected via an online post on LinkedIn in January 2019. A grand total of 95 responses were received.

\section{RESULTS}

The dataset was screened and four questionnaires were dropped due to lack of commitment in the responses. The criterion for deletion was questionnaires with a standard deviation of less than 0.5. The participants's years of experience were as follows: $13.3 \%$ had more than 15 years of experience, $16.7 \%$ had 11 to 15 years of experience, $32.2 \%$ had 6 to 10 years of experience, and $37.8 \%$ had less than 5 years of experience. Additionally, participants' years of experience using LPS were as follows: $8.9 \%$ had more than 9 years of LPS experience, $5.6 \%$ had 7 to 9 years of experience, $28.9 \%$ had 4 to 6 years of LPS experience, and $56.7 \%$ had less than 3 years of LPS experience. Participant's demographics show a breadth of professional experience in construction and represents the experience of innovators, early adopters and the early majority (Rogers 2003). From a firm size perspective, $49.5 \%$ of the respondents work in small firms (1-50 employees), $27.5 \%$ in medium-sized firms (51-250 employees), and 22.0\% in large firms (>250 employees). Similarly, the demographics of projects were as follows: $27.0 \%$ of project $\leq 5,000 \mathrm{sqm}$, $21.3 \%$ of projects between 5,001 and $10,000 \mathrm{sqm}, 30.3 \%$ of projects between 10,001 and $20,000 \mathrm{sqm}$, and $21.3 \%$ projects $>20,000 \mathrm{sqm}$. Firms' and projects' demographics confirm a sample containing firms and projects covering the range found in the industry. Therefore, the sample is considered to be reliable.

The Cronbach Alpha $(\alpha)$ was calculated for each factor to assess the reliability of observed variables, this is, that the variables in the questionnaires are measuring the unobserved factor (e.g. commitment is measured with five variables as shown in Table 1). Academic literature recommends a threshold of 0.70 as a minimum value to accept the 
variables measuring the factor. However, in exploratory studies it can be accepted values $\geq 0.60$.

Mean responses of the factors can be considered as indicators of the importance of the factors that contribute to the use of LPS methods. The factors were arranged in descending order of mean values and ranked. Depending on the mean scores and standard deviations, the factors can be divided into two groups: group 1 with mean scores $\geq 3.5$ represent the more important factors present in construction projects, and group 2 with mean scores < 3.5 represent factors with significantly less importance. As shown in Table 2, a total of 5 factors are in group 1, and 4 factors are in group 2. 'Trained staff', 'good information and decision-making', 'commitment', and 'leadership' stand out as the most prominent success factors in the LPS.

Table 2: Descriptive statistics of factors influencing the use of LPS methods

\begin{tabular}{lcccc}
\hline Factor & Mean & S.D. & Rank & Cronbach $\boldsymbol{\alpha}$ \\
\hline Trained staff & 4.05 & 0.83 & 1 & 0.65 \\
Good information and decision-making & 3.93 & 0.82 & 2 & 0.75 \\
Commitment & 3.79 & 0.72 & 3 & 0.76 \\
Leadership & 3.60 & 0.79 & 4 & 0.77 \\
Integration and communication & 3.55 & 0.73 & 5 & 0.67 \\
Firm's LPS-culture & 3.44 & 0.86 & 6 & 0.70 \\
LPS-knowledge & 3.43 & 0.85 & 7 & 0.68 \\
Resistance to change & 3.13 & 0.92 & 8 & 0.64 \\
Lack of time & 3.05 & 1.05 & 9 & 0.90 \\
\hline
\end{tabular}

Table 3 shows the mean score, standard deviation and the rank of the dependent variables (LPS methods). It is observed that none of the methods obtain a mean score of $\geq 4$ (High or Very High). On the one hand, Master schedule, pull planning (structure phase), constraints analysis and removal have higher scores. On the other hand, PCC, analysis of breakdowns and reliable promising have the lowest scores (mean $\leq 3.5$ ).

Multiple regression analysis was also used to establish relationships between dependent (LPS methods) and independent factors (9 factors). A stepwise procedure was applied and four independent factors were selected. Altogether, $49 \%$ of the LPS methods' variance was explained by 'Integration and Communication', 'LPS-Knowledge', 'Resistance to Change', and 'the firm size', which were significantly different from zero at a $p \leq 0.05$. 'Integration and Communication' contribute significantly to the use of LPS methods $\left(R^{2}=0.29\right.$, $\mathrm{p}<0.001$ ), whilst 'LPS-knowledge' and 'Resistance to Change' accounted for $13 \%$ and $4 \%$ of the variance respectively. The firm size accounted for $3 \%$ of the variance. Table 4 shows the unstandardized regression coefficients $(\beta)$, the standard error (S.E.), the t-statistic $(t)$, and the significance level ( $\mathrm{p}$-value). 
Table 3: Mean scores, standard deviation, and rank of LPS methods

\begin{tabular}{lccc}
\hline LPS Method & Mean & S.D. & Rank \\
\hline Master schedule & 3.91 & 0.91 & 1 \\
Pull Planning (Structures Phase) & 3.74 & 1.00 & 2 \\
Constraint Analysis and Removal & 3.63 & 1.03 & 3 \\
Task Breakdown & 3.55 & 0.82 & 4 \\
Weekly Planning Meetings & 3.54 & 1.06 & 5 \\
Pull Planning (Finishing Phase) & 3.53 & 0.94 & 6 \\
PPC Metric & 3.46 & 1.24 & 7 \\
Analysis of Breakdowns & 3.43 & 1.09 & 8 \\
Reliable Promising & 3.21 & 1.01 & 9 \\
\hline
\end{tabular}

Table 4: Results of Stepwise Multiple Linear Regression $\left(\mathrm{R}^{2}=0.49\right)$

\begin{tabular}{lcccc}
\hline Variable & $\boldsymbol{\beta}$ & S.E. & $\mathbf{t}$ & p-value \\
\hline (Constant) & 1.761 & 0.369 & 4.774 & $0.000^{*}$ \\
Integration and communication & 0.393 & 0.075 & 5.226 & $0.000^{*}$ \\
LPS-knowledge & 0.286 & 0.064 & 4.478 & $0.000^{*}$ \\
Resistance to Change & -0.152 & 0.064 & -2.378 & 0.020 \\
Firm Size (Small Firm) & -0.245 & 0.106 & -2.319 & 0.023 \\
\hline
\end{tabular}

$* \mathrm{p}<0.001$. Sample size $\mathrm{N}=91$

\section{DISCUSSION}

'Integration and Communication' was shown to be the most important factor contributing to the deployment of LPS methods $(\beta=0.39, \mathrm{p}<0.000)$. This factor also represents two key elements pertaining to integration: 'leadership' and 'commitment'. Although 'leadership' and 'commitment' were not significant factors in the stepwise regression analysis, the correlation coefficient between 'leadership' and 'integration and communication' was 0.59 $(\mathrm{p}<0.000)$ and the correlations coefficient between 'commitment' and 'integration and communication' was 0.52 ( $\mathrm{p}<0.000)$. This finding suggests a causality relationship between 'leadership' and 'commitment' to 'integration and communication' that can be further explored.

'LPS-knowledge' was found to be the second key factor contributing to LPS deployment $(\beta=0.29, \mathrm{p}<0.000)$. This finding is consistent with previous studies (Alarcon et al. 2005; Friblick et al. 2009; Fernandez-Solis et al. 2012). Friblick et al. (2009) found that the knowledge of LPS among construction managers is low in the Swedish 
construction industry. In order to manage successful implementation, Friblick et al. (2009) stated that LPS knowledge should be clarified to practitioners who execute tasks. However, learning LPS requires standardised and permanent training. Moreover, training can be a direct consequence of institutional factors such as 'firm's LPS-culture' or 'top management support'. As noted by Dave et al. (2015), the people perspective requires a focus on training and a consistent approach to teaching LPS across universities and consultants.

The question remains whether small firms can tackle the level of training required by LPS. Although some scholars argue that the small firm is a good environment for implementing changes due to their flexibility and dynamism, this study has found that the small firm deploys fewer LPS methods compared to medium and large firms $(\beta=-0.25$, $\mathrm{p}<0.05)$. Additionally, the results show that there was not a significant difference in LPS implementation between medium and large contractors. This result suggests that small firms have not developed a within-firm LPS culture, thus, a lack of a standardised LPS system for production management and control. By contrast, some medium and large firms did have implemented LPS as the institutional production management system, and engineers are trained to deploy its methods. Nevertheless, 'resistance to change' is the human factor that was found to be the second barrier for LPS implementation across small, medium, and large contractors $(\beta=-0.15, \mathrm{p}<0.05)$. Therefore, a meaningful participation of project stakeholders is required. Hamzeh (2011) stated that implementing LPS in a project is more than applying tools. It requires a change on the way "people think, work, and execute tasks". It is argued that resistance to change is overcome when people profoundly understand the benefits of implementation in contrast to the effects of non-implementation.

Fernandez-Solis et al. (2012) emphasised the importance to recognise the challenges for LPS implementation and to tackle these challenges to increase the level of adoption in projects and organisations. The two main factors and the two main barriers found in this study can be managed by site engineers and decision-makers to tackle the deficiencies in LPS implementation. For a current LPS user, the firm discourse on LPS should be consistent with a standardised approach that includes training to enhance the 'LPSknowledge' of site engineers, foreman, and subcontractors; overcome 'resistance to change' and foster the levels of 'integration and communication'. Nonetheless, Hamzeh (2011) posited that successful implementation of LPS requires a deep change at the institutional level. LPS offers a methodological framework for construction planning, however, it will only work if the firm embraces a lean culture.

\section{CONCLUSIONS}

Empirical evidence of previous research suggests the partial implementation of LPS worldwide. This research aimed to identify the most prominent factors that influence and constrain the deployment of LPS methods, thus, site engineers and decision-makers are aware of and can handle them. 'Integration and Communication', and 'LPS-knowledge' were found to be the most important facilitators. 'Integration and Communication' requires effective stakeholder's integration, compatible decisions, and permanent feedback between site engineers, subcontractors, and last planners. 'LPS-knowledge' requires standardised training on the concepts involved to implement LPS onsite. Training requires an 
institutional investigation of the common understanding of LPS in specific contexts. It was also found that small firms struggle to implement LPS. This finding can be further investigated on why the small firm which is deemed to be flexible and adaptable cannot handle the required LPS change. Finally, 'resistance to change' is a human factor present in the diffusion of process and technological innovations. Previous research has found that it can be handled at the firm level.

\section{ACKNOWLEDGMENTS}

The author would like to thank the graduate student at PUCP, Fabrizio Alarcon, who kindly collected the data at the construction sites. The author also thanks LCI (Peru) Chapter for the diffusion of the online questionnaire.

\section{REFERENCES}

Alarcon, L.F., Diethelm, S., Rojo, O. \& Calderon, R., (2005). Assessing the impacts of implementing lean construction. In 13th Annual Conference of the International Group for Lean Construction. Sidney, Australia, pp. 387-393.

Alarcon, L.F., Diethelm, S. \& Rojo, O., (2002). Collaborative implementation of lean planning systems in Chilean construction companies. In 10th Annual Conference of the International Group for Lean Construction. Gramado, Brazil, pp. 541-551.

Ballard, G. \& Tommelein, I., (2016). Current Process Benchmark for the Last Planner $®$ System. Lean Construction Journal, 89, pp.57-89.

Brady, D., Tzortopoulos, P. \& Rooke, J., (2011). An Examination of the Barriers To Last Planner Implementation. In 19th Annual Conference for Lean Construction. Lima, Peru.

Cano, S., Delgado, J., Botero, L. \& Rubiano, O., (2015). Barriers and success factors in lean construction implementation-survey in pilot context. In 23rd Annual Conference of the International Group for Lean Construction. Perth, Australia, pp. 631-641.

Cresswell, J.W., (2014). Research Design. Qualitative, Quantitative and Mixed methods approaches 4th ed., London: Sage.

Dave, B., Hämäläinen, J.-P. \& Koskela, L., (2015). Exploring the Recurrent Problems in the Last Planner Implementation on Construction Projects. In Proceedings of the Indian Lean Construction Conference (ILCC 2015). pp. 1-9.

Ebbs, P. \& Pasquire, C., (2019). A Facilitators' Guide to the Last Planner ${ }^{\circledR}$ System : A Repository of Facilitation Tips for Practitioners, Nottingham Trent University.

Fernandez-Solis, J. et al., (2012). Survey of Motivations, Benefits, and Implementation Challenges of Last Planner System Users. Journal of Construction Engineering and Management, 139(4), pp.354-360.

Flores, G. \& Ollero, C., (2013). Productivity improvement applying production management in projects with repetitive activities. In 21st Annual Conference of the International Group for Lean Construction. Fortaleza, Brazil, pp. 160-169.

Friblick, F., Olsson, V. \& Reslow, J., (2009). Prospects for implementing Last Planner in the construction industry. In 17th Annual Conference of the International Group for Lean Construction. Taipei, Taiwan, pp. 197-206. 
Guio, V., (2001). Productividad en Obras de Construcción, Lima: Pontificia Universidad Catolica del Peru.

Hamzeh, F., (2011). The Lean Journey: Implementing The Last Planner ${ }^{\circledR}$ System in Construction. In 19th Conference for the International Group of Lean Constrution. Lima, Peru, pp. 379-390.

Murguia, D., Brioso, X. \& Pimentel, A., (2016). Applying lean techniques to improve performance in the finishing phase of a residential building. In 24th Annual Conference of the International Group for Lean Construction. Boston, USA, pp. 4352.

Perez, A.M. \& Ghosh, S., (2018). Barriers faced by new-adopter of Last Planner System®: a case study. Engineering, Construction and Architectural Management, 25(9), pp.1110-1126.

Rogers, E.M., (2003). Diffusion of Innovations, New York: The Free Press.

Yoza, A., (2011). Impact of "The Last Planner®" Method on Sanitation Works. In 19th Conference for the International Group of Lean Constrution. Lima, Peru, pp. 195203. 